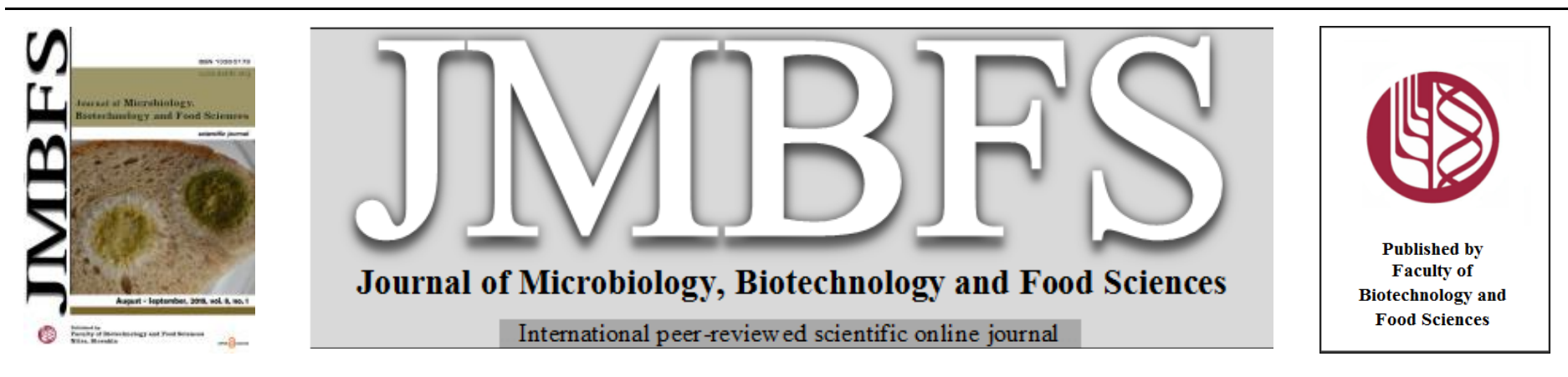

\title{
IN-VITRO ANTIBACTERIAL, PHYTOCHEMICAL, ANTIMYCOBACTERIAL ACTIVITIES AND GC-MS ANALYSES OF Bidens pilosa LEAF EXTRACT
}

\author{
Christiana Ajanaku*1, Johnbull Echeme ${ }^{2}$, Raphael Mordi ${ }^{1}$, Oladotun Bolade ${ }^{1}$, Stella Okoye ${ }^{1}$, Hassana Jonathan ${ }^{1}$, Oluwaseun Ejilude ${ }^{3}$
}

Address(es):

${ }^{1}$ Department of Chemistry, Covenant University, P.M.B. 1023, Ota, Ogun State, Nigeria.

${ }^{2}$ Department of Chemistry, Michael Okpara University of Agriculture, Umudike, Owerri, Imo State, Nigeria.

${ }^{3}$ Department of Medical Microbiology and Parasitology, Sacred Heart Hospitals, Lantoro, Abeokuta, Ogun State, Nigeria.

*Corresponding author: oluwatoyin.ajanaku@covenantuniversity.edu.ng

doi: 10.15414/jmbfs.2018.8.1.721-725

ARTICLE INFO

Received 29. 5. 2018

Revised 3. 7. 2018

Accepted 3. 7. 2018

Published 1. 8. 2018

Regular article

open $\partial_{\text {ACCESS }}$

\begin{abstract}
The phytochemical constituents, antimicrobial activity, anti-mycobacterial activity and gas chromatography-mass spectrometry (GCMS) analysis of the West African ecotype of Bidens pilosa was investigated for possible medicinal properties. The antimicrobial activity of the hexane, dichloromethane, ethyl acetate and methanol extracts from the leaf of Bidens pilosa was evaluated using agar dilution method. The qualitative and quantitative phytochemical screening was carried out according to standard procedures. Partitioned fractions of the methanolic extract was subjected to anti-mycobacterial bioassay. Different fractions of the leaf were subjected to GCMS to ascertain the compounds present. The antimicrobial analysis revealed the methanolic fraction as having the highest number of activity against test organisms such as: Bacillus subtilis, Escherichia coli, Klebsiella pneumoniae, Pseudomonas aeruginosa, Candida albicans and Rhizopus sp. between $10-40 \mathrm{~mm}$. The minimum inhibitory concentration showed the methanolic fraction to be active against Candida albicans and Rhizopus sp. at the concentration of $6.25 \mathrm{~g} / \mathrm{ml}$ and $3.25 \mathrm{~g} / \mathrm{ml}$ respectively. The phytochemical screening revealed the presence of alkaloids, cardiac glycosides and terpenoids in all the solvents. Tannin was present in all the solvent fractions except hexane fraction. Saponin was not found in any of the solvents. The hexane-methanol interface of the partitioned solvents was sensitive to the anti-mycobacterial activity while other solvents showed resistance. The GC-MS and the chromatogram gave insight into the volatile components of the leaf extract. The findings reveals Bidens pilosa as a medicinal plant with potentials for the treatment of tuberculosis.
\end{abstract}

Keywords: Phytochemicals, Bidens pilosa, antimicrobial, anti-mycobacterial, medicinal plants, infectious diseases, Tuberculosis

\section{INTRODUCTION}

The use of alternative medicine, by developing countries is being fuelled by the concern of adverse effects of chemical drugs (WHO, 2002). Human health preservation greatly depends on the use of plants; which serves as sources of food and medicines (Hamilton, 2004). It is widely reported that about $80 \%$ of the world population rely mostly on herbal medicines to meet their basic health needs (Sofowora, 1996). The medicinal application of natural products has been found useful since natural product has been discovered to have therapeutic and healing properties. Among the Nigerian natives, the ethno pharmacological use of plants prevails. Some of the ailments which plants have been used to treat include: malaria, diarrhoea, burns, gonorrhoea, stomach disorders and other infectious diseases (Aibinu et al., 2007). The use of fruits, for instance, soursop fruit was been found to be effective in the destruction of cancer and is a thousand times more effective than chemotherapy. Other fruits include the use of garlic, onions, turmeric, carrots, apples among others (Cooper, 2015). Current global trends in drug synthesis have shown the increasing significance of plants in medicine. The potency of these plants is as a result of the presence of active components it contains. These compounds have specific roles it carries out on definite sites within the body system (Ijeh et al, 2004). The effect of drugs on the physiological system is specific in action and dependent on the presence of bioactive molecules that are of plant origin (Nweze et al,. 2004). Such bioactive compounds sourced from plants contain antimicrobial and antioxidant properties. Infectious diseases like tuberculosis is caused by Mycobacterium tuberculosis (Kumar et al., 2007). The development of multi-drug resistance has constituted a growing threat to global TB program. Researchers have gone into solving problems of resistance to specific drugs such as pyrazinamide, isoniazid and PA824. This has resulted in need for more drugs to combat multi-drug resistance to tuberculosis (Olugbuyiro et al., 2009).

Bidens pilosa is often considered as a weed plant and can be found in Japan, China, America and Africa. Although, it is commonly believed to have originated from South America, it is distributed widely in the subtropical and tropical regions. The Bidens pilosa is commonly called grab-a-leg, Spanish needles, cobbler's pegs, sticky beak, pitchforks, hairy tick weed, broomstick, blackjack, demon spike grass or ghost needle weed (Bartolome et al., 2013). It is a slender, yearly, erect, branching herb that grows up to $1.5 \mathrm{~m}$ average height and $2.0 \mathrm{~m}$ in good condition. It grows around maize, vegetables, pasture, sorghum, coffee, cassava, cotton, coconut, tea, citrus, rubber, oil palm, papaya, tobacco and rice as a weed (Connelly, 2009). Studies have shown that Bidens pilosa is used in traditional medicine, the herbal plant have numerous health benefits used in the treatments of colds, flu, fever, wounds, jaundice, neuralgia, small pox, hepatitis, glandular sclerosis, snake bite, anaemia, colic, diuretic, conjunctivitis and diarrhoea (Bartolome $\boldsymbol{e t}$ al., 2013). Biochemical activities of the plant genus are directly related to the presence of secondary metabolites in the plants. (Adebayo et al, 2017). The focus of this paper was to investigate the phytochemical, antibacterial, anti-mycobacterial and GC-MS analysis of the leaf of Bidens pilosa plant which belongs to the family Asteraceae.

\section{MATERIALS AND METHODS}

\section{Collection of Bidens pilosa leaf}

The leaf of Bidens pilosa free from infection was collected from Iyana Iyesi village of Ota, in Ogun state. The Local Government Area is Ado-odo Ota, is located at $6^{\circ} 41^{\prime} \mathrm{N} 3^{\circ} 41^{\prime} \mathrm{E}$ to the north of the area. Plant samples was authenticated at the herbarium section of the Forest Research Institute of Nigeria with voucher No FHI 110016. The leaf part of the plant was used to prepare the extract. The plant collected was rinsed with water to remove the dirt particles and air dried. The dried leaf was hand pulverised, grinded to fine powder and stored till further use. 


\section{Extraction of Bidens pilosa leaf}

The fine powder of the Bidens pilosa leaf were dried and was extracted with different solvents of hexane, ethyl acetate, dichloromethane and methanol by cold extraction at an average of $29^{\circ} \mathrm{C}$ room temperature for 72 hours. The filtered portions were concentrated using a rotary evaporator and stored for further analysis.

\section{Phytochemical screening of Bidens pilosa leaf}

Phytochemical determination for the presence of reducing sugars, anthraquinones, terpenoids, saponins, alkaloids, oils and fats, flavonoids, tannins, and cardiac glycosides were carried out on all the extracts using standard qualitative methods as described by Sofowora (1996). The qualitative phytochemical screening was carried out on each of the extracts obtained from hexane, ethyl acetate, dichloromethane and methanol solutions.

\section{Test for Carbohydrates}

To $2 \mathrm{~mL}$ of plant extracts, $1 \mathrm{~mL}$ of Molisch's reagent and few drops of concentrated sulphuric acid was added. Purple colour formation indicated the presence of carbohydrates.

\section{Test for Tannins}

To $1 \mathrm{~mL}$ of plant extract, $2 \mathrm{~mL}$ of $5 \%$ ferric chloride was added. Formation of greenish black indicated the presence of tannins.

\section{Test for Saponins}

To $2 \mathrm{~mL}$ of plant extract, $2 \mathrm{~mL}$ of distilled water was added and shaken in a graduated cylinder for 15 minutes lengthwise. Formation of $1 \mathrm{~cm}$ layer of foam indicated the presence of saponins.

\section{Test for Flavonoids}

$5 \mathrm{~mL}$ of dilute ammonia solution was added to $1 \mathrm{~mL}$ of the aqueous filtrate of plant extract followed by addition of concentrated sulphuric acid. Appearance of yellow coloration indicated the presence of flavonoids.

\section{Test for Alkaloids}

To $2 \mathrm{~mL}$ of plant extract, $2 \mathrm{ml}$ of concentrated hydrochloric acid was added. Then few drops of Mayer's reagent was added. Presence of green colour indicated the presence of alkaloids.

\section{Test for Anthocyanin and Betacyanin}

To $2 \mathrm{~mL}$ of plant extract, $1 \mathrm{~mL}$ of $2 \mathrm{M}$ sodium hydroxide was added and heated for 5 minutes at $100^{\circ} \mathrm{C}$. Formation of yellow colour indicated the presence of betacyanin.

\section{Test for Quinones}

To $1 \mathrm{~mL}$ of extract, $1 \mathrm{~mL}$ of concentrated sulphuric acid was added. Formation of red colour indicated the presence of quinones.

\section{Test for Glycosides}

To $2 \mathrm{~mL}$ of plant extract, $3 \mathrm{~mL}$ of chloroform and $10 \%$ ammonia solution was added. Pink colour formation indicated the presence of glycosides.

\section{Test for Cardiac glycosides}

To $0.5 \mathrm{~mL}$ of extract, $2 \mathrm{~mL}$ of glacial acetic acid and few drops of $5 \%$ ferric chloride were added. $1 \mathrm{~mL}$ of concentrated sulphuric acid was added. Brown ring formation at the interface indicated the presence of cardiac glycosides.

\section{Test for Terpenoids}

To $0.5 \mathrm{~mL}$ of extract, $2 \mathrm{ml}$ of chloroform was added and concentrated sulphuric acid was added carefully. Red brown colour formation at the interface indicated the presence of terpenoids.

\section{Test for Triterpenoids}

To $1.5 \mathrm{~mL}$ of extract, $1 \mathrm{~mL}$ of Libermann-Buchard Reagent (acetic anhydride + concentrated sulphuric acid) was added. Blue green colour formation indicated the presence of triterpenoids.

\section{Test for Phenols}

To $1 \mathrm{~mL}$ of the extract, $2 \mathrm{~mL}$ of distilled water followed by few drops of $10 \%$ ferric chloride was added. Formation of green colour indicated the presence of phenols.

\section{Test for Coumarins}

To $1 \mathrm{~mL}$ of extract, $1 \mathrm{ml}$ of $10 \%$ Sodium hydroxide was added. Formation of yellow colour indicated the presence of coumarins.

\section{Test for steroids}

To $2 \mathrm{~mL}$ of the extract $5 \mathrm{~mL}$ of chloroform was added and filtered, $2 \mathrm{~mL}$ of acetic anhydride was added to $2 \mathrm{~mL}$ of filtrate with $2 \mathrm{~mL}$ of sulphuric acid. The colour changes from violet to blue or green this indicates the presence of steroids.

\section{Test for Acids}

$1 \mathrm{~mL}$ of extract was treated with sodium bicarbonate solution. Formation of effervescence indicates the presence of acids.

\section{Antibacterial activity bioassay of Bidens pilosa leaf}

The extracts were evaluated for antibacterial activity against Bacillus spp, Escherichia coli, Pseudomonas aeruginosa, Staphylococcus aureus, Micrococcus varians, Serratia spp, and Aspergillus niger, using Sabouraud dextrose agar as the medium.

\section{Determination of Minimum Inhibitory Concentration (MIC)}

Minimum inhibitory concentration was carried out on the leaf of Bidens pilosa using the method described by Mahesh and Satish (2008). The procedure, using nutrient agar as medium was carried out on the different fractions of B. pilosa leaf that showed sensitivity against the growth of some selected organisms. These fractions were adjusted to $50,25,12.5,6.25,3.125$ and $1.562 \mathrm{mg} / \mathrm{ml}$ concentrations by serial dilution method. The sterile nutrient agar plates were seeded using swab sticks with the test organisms or isolates of $0.5 \%$ McFarland standard. Sterile cork borer was used to bore wells of about $9 \mathrm{~mm}$ in diameter into the sterile nutrient agar plates. Sterile pipette of $1 \mathrm{~mL}$ were used to measure $0.2 \mathrm{~mL}$ of each extract of different concentrations into the bored wells on the inoculated nutrient agar plates. The plates were observed for growth and death of test organisms after incubation at $37^{\circ} \mathrm{C}$ for 24 hours. Gentamycin, with a concentration of $10 \mu \mathrm{g}$ was used as the standard antibiotic.

\section{Anti-mycobacterial susceptibility test}

The methanolic crude extract of the leaf part was partitioned into different solvents using: aqueous, chloroform, methanol and hexane. Each of the solvent fractions were subjected to bio-assay against mycobacterial activity. Antimycobacterial susceptibility test was performed by proportion method as described by FMOH (2009). The Mycobacterium tuberculosis isolates (drug susceptible and drug resistant) were tested against the partitioned fractions, rifampicin and levofloxacin (Sigma scientific laboratories USA)

The proportion method was carried out from a subculture on Lowenstein-Jensen (L-J) medium. A representative sample of $5.0 \mathrm{mg}$ to $10.0 \mathrm{mg}$ from the sub-culture was obtained within 1 to 2 weeks after appearance of growth using a calibrated inoculating loop. Samples were placed into a sterile McCartney bottle (14 mL screw capped bottle) containing $1.0 \mathrm{~mL}$ distilled water and 10 glass beads. The mixture was homogenized on a vortex mixer for 1 minute and the opacity of the suspension was adjusted by the addition of sterile distilled water to a standard suspension containing $1 \mathrm{mg} / \mathrm{mL}$ of Mycobacterium tuberculosis isolates.

Two serial dilutions were made from the suspension $10^{-2} \mathrm{mg} / \mathrm{mL}$ and $10^{-4} \mathrm{mg} / \mathrm{mL}$ using the calibrated inoculating loop and sterile McCartney vials containing 1.0 $\mathrm{mL}$ of distilled water. $0.1 \mathrm{~mL}$ of $10^{-2}$ and $10^{-4}$ suspensions were inoculated onto 2 slants of drug/extract free (control) medium. The suspensions were spread over the surface of the medium and kept at a slanting position with loosen caps. The seeded media were examined for contamination after 1 week .The slants were incubated at $37^{\circ} \mathrm{C}$. When the growth appeared on the control medium, the cap to the vial was tightened and incubation continued for 4 weeks.

When enough growth, more than 100 colonies for $10^{-2}$ suspension and more than 50 colonies for $10^{-4}$ suspension, was observed on the drug/extract free medium a 4 weeks of incubation, the growth on all media was read. For strains showing drug susceptibility at 4 weeks, further reading was taken at 6 weeks. Quality control strains-H37RV was included in each batch of testing.

The first reading of antimycobacterial susceptibility test result was done at 4 weeks ( 28 days) of incubation at $37^{\circ} \mathrm{C}$. The growth on the drug/extract containing medium was compared with the growth on the drug/extract free medium at $10^{-4}$ dilution. When the growth on the drug/extract containing medium was none or 
less than that of a drug/extract free medium at $10^{-4}$ dilution, the drug/extract was classified as susceptible/sensitive.

The following formula was used to calculate the percent resistant:

$\%$ Resistance $=\frac{\text { Number of colonies on drug containing medium }}{\text { Number of colonies on the drug free medium at } 10^{-4} \text { dilution }}$

The criteria for resistance is $1 \%$ of growth for all the drugs/extracts. No growth or less than $1 \%$ of colonies growing compared to the controls (Fujiki, 2001).

\section{Quantitative phytochemical evaluation}

The total flavonoid in the Bidens pilosa leaf extracts was determined using the aluminium chloride colorimetric assay in accordance with the method of Kalita et al., (2013) while the tannin and phenol contents determination was carried out using Folin-ciocalteu's spectrophotometric method of Nkafamiya (2006) and Dewanto (2002) respectively. The alkaloid percentage was then estimated using the Ladan et al., (2014) method while the total steroid content was measured spectrophotometrically by Lieberman-Burchard method of Sathishkumar and Baskar (2014).

\section{GC-MS analysis of Bidens pilosa leaf}

GC-MS analysis of the leaf of Bidens pilosa extract was analysed using the equipment Agilent 7890A Gas Chromatography-Mass spectrometry system with Mass hunter acquisition software. The equipment has a HP-5MS ultra inert capillary non-polar column with dimensions of $30 \mathrm{~mm} \times 0.25 \mathrm{~mm} \mathrm{ID} \times 0.25 \mu \mathrm{m}$ film. The carrier gas used is Helium with at flow of $1.0 \mathrm{ml} / \mathrm{min}$. The injector was operated at $250{ }^{\circ} \mathrm{C}$ and the oven temperature was programmed as follows: $50{ }^{\circ} \mathrm{C}$ for $5 \mathrm{~min}$, then gradually increased to $250^{\circ} \mathrm{C}$ at $10^{\circ} \mathrm{C} / \mathrm{min}$, and finally to $300^{\circ} \mathrm{C}$ a $7{ }^{\circ} \mathrm{C} / \mathrm{min}$ for $10 \mathrm{~min}$. The identification of components was determined by comparison with the NIST library data while the percentage composition was computed from GC peak areas.

\section{RESULTS AND DISCUSSION}

The results of phytochemical screening of the B. pilosa leaf extract indicated the appearance of the following secondary metabolites: carbohydrates, alkaloids, flavonoids, phenolic compounds, anthocyanins, quinones, terpenoids, triterpenoids, steroids and cardiac glycosides (Table 1). Particularly, hexane, dichloromethane, ethyl acetate and methanol extracts of $B$. pilosa were good sources of different classes of compounds. Alkaloids, cardiac glycosides and terpenoids were present in all the solvent extracts. This could be a useful insight in the possible compounds that could be isolated from the plant material. It is also observed that in all the solvent fractions, saponin was absent. Tannin was present in all the solvent fractions except in hexane fraction. Steroids and Triterpenoids are present in all the solvents except in methanolic fraction. Carbohydrates, flavonoids and quinones were present in the hexane and methanolic fractions but were absent in dichloromethane and ethyl acetate fractions. Anthocyanin and betacyanins, quinones were found only in the hexane solvent.
Table 1 Phytochemicals present in leaf fraction of Bidens pilosa with their intensities

\begin{tabular}{lcccc}
\hline & \multicolumn{4}{c}{ Intensity } \\
\cline { 2 - 5 } Constituents & $\begin{array}{c}\text { Hexane } \\
\text { Fraction }\end{array}$ & $\begin{array}{c}\text { Dichloromethane } \\
\text { Fraction }\end{array}$ & $\begin{array}{c}\text { Ethyl } \\
\text { Acetate } \\
\text { Fraction }\end{array}$ & $\begin{array}{c}\text { Methanol } \\
\text { Fraction }\end{array}$ \\
\hline Carbohydrates & +++ & - & - & +++ \\
Tannins & - & +++ & +++ & +++ \\
Saponins & - & - & - & - \\
Flavonoids & +++ & - & - & +++ \\
Alkaloids & +++ & +++ & +++ & ++ \\
Anthocyanin & +++ & - & - & - \\
\& Betacyanin & +++ & - & - & ++ \\
Quinones & ++ & - & - & +++ \\
Glycosides & - & +++ & +++ & +++ \\
Cardiac & +++ & ++ & +++ & +++ \\
Glycoside & +++ & ++ & - \\
Terpenoids & +++ & +++ & +++ & - \\
Triterpenoids & ++ & +++ & - \\
Phenols & - & ++ & - & - \\
Coumarins & +++ & ++ & ++ & - \\
Steroids & +++ & +++ & - & \\
Acids & - & - & & +
\end{tabular}

Phenols are present in the dichloromethane and ethyl acetate fractions but absent in hexane and methanol fractions. Also, the hexane and dichloromethane fractions contained the coumarins, which is absent in ethyl acetate and methanol. Steroids were present in all the solvents except the methanol fraction. Glycosides were found present only in the methanolic fraction. The results of the phytochemicals is in line with previous studies made by Bartolome $\boldsymbol{e t}$ al., 2013 and Yang, 2014.

Table 2 Quantitative Phytochemical Analysis of Bidens pilosa leaf extract

\begin{tabular}{lccccc}
\hline Fractions & $\begin{array}{c}\text { Total } \\
\text { Alkaloid } \\
(\boldsymbol{\%})\end{array}$ & $\begin{array}{c}\text { Total } \\
\text { Flavonoid } \\
(\boldsymbol{\%})\end{array}$ & $\begin{array}{c}\text { Total } \\
\text { Phenol } \\
(\boldsymbol{\%})\end{array}$ & $\begin{array}{c}\text { Total } \\
\text { Tannin } \\
(\boldsymbol{\%})\end{array}$ & $\begin{array}{c}\text { Total } \\
\text { Steroids } \\
(\boldsymbol{\%})\end{array}$ \\
\hline Hexane & 0.80 & 0.23 & - & - & 0.14 \\
DCM & 0.92 & - & 0.26 & 0.78 & - \\
Ethyl & - & - & 0.33 & 0.70 & 1.31 \\
acetate & & - & - & 0.61 & - \\
Methanol & 1.12 & 0.35 & - & \\
\hline
\end{tabular}

The quantity of the most common phytochemicals present in the leaf of B. pilosa is presented in Table 2. It was observed that steroids were more abundant in the ethyl acetate fraction while the alkaloids were present in all the fractions except in ethyl acetate. Tannins were moderately present in all fractions except for Hexane fraction. Phenols were present in small amounts in dichloromethane and ethyl acetate. Flavonoids were present in small amounts in hexane and methanol.

Table 3 Zones of inhibition (in $\mathrm{mm}$ ) of leaf fractions of Bidens pilosa against selected microorganisms

\begin{tabular}{|c|c|c|c|c|c|}
\hline \multirow[b]{2}{*}{ Organism } & \multicolumn{5}{|c|}{ Zone of inhibition in millimetres for the $B P$ leaf } \\
\hline & $\begin{array}{l}\text { Hexane } \\
\text { fraction }\end{array}$ & $\begin{array}{c}\text { Dichloromethane } \\
\text { Fraction }\end{array}$ & $\begin{array}{c}\text { Ethyl acetate } \\
\text { Fraction }\end{array}$ & $\begin{array}{c}\text { Methanol } \\
\text { Fraction }\end{array}$ & $\begin{array}{c}\text { Control } \\
\text { (gentamycin) }\end{array}$ \\
\hline Bacillus subtilis & 10 & - & 15 & 11 & 15 \\
\hline Escherichia coli & - & - & - & 15 & - \\
\hline Klebsiella pneumoniae & - & - & - & 10 & 16 \\
\hline Pseudomonas aeruginosa & - & - & 14 & 16 & 10 \\
\hline Staphylococcus aureus & - & - & - & - & 8 \\
\hline Candida albicans & 10 & 20 & - & 40 & - \\
\hline Rhizopus sp. & - & - & 11 & 10 & - \\
\hline
\end{tabular}

Table 4 Minimum inhibitory concentration of Bidens pilosa leaf fractions against selected microorganisms $(\mathrm{mg} / \mathrm{ml})$

\begin{tabular}{lllllllllll} 
Organism & & \multicolumn{3}{c}{ Methanol Fraction } & \multicolumn{3}{c}{$\begin{array}{c}\text { Dichloromethane } \\
\text { Fraction }\end{array}$} \\
\hline $\begin{array}{l}\text { Candida } \\
\text { albicans } \\
\text { Rhizopus }\end{array}$ & - & - & - & 6.25 & - & & & & & \\
\hline
\end{tabular}

For the antimicrobial analysis, Table 3 showed the zones of inhibition against various test organisms. The methanolic fraction showing the highest number of activity against test organisms which were $11 \mathrm{~mm}, 40 \mathrm{~mm}, 15 \mathrm{~mm}, 10 \mathrm{~mm}, 16$ $\mathrm{mm}$, and $10 \mathrm{~mm}$ against Bacillus subtilis, Candida albicans, Escherichia coli, Klebsiella pneumoniae, Pseudomonas aeruginosa, and Rhizopus sp. respectively. This was followed by the ethyl acetate fraction showing zones of inhibition at 11 $\mathrm{mm}, 14 \mathrm{~mm}$ and $15 \mathrm{~mm}$ against Rhizopus sp., Pseudomonas aeruginosa and Bacillus subtilis respectively. At $10 \mathrm{~mm}$, the hexane fraction showed inhibition against Bacillus subtilis and Candida albicans; while the dichloromethane fraction showed inhibition at $20 \mathrm{~mm}$ against Candida albicans only. It can be deduced that methanolic fraction of the $B P$ leaf is more active against the test organisms and hence can inhibit their growth. In view of the result obtained from the zones of inhibition further processes to situate the minimum inhibitory concentration was carried out and the result is shown in Table 4. The MIC was found at 3.125 against Candida albicans, while the methanolic fraction also had 3.125 concentration against Rhizopus sp. This implies that the BP leaf has both anti-bacterial and anti-fungi properties.

The modern practice being used presently in identifying the active components present in crude extracts is bioassay-guided fractionation.

The result in Table 5 revealed that the hexane/methanol fraction exhibited good anti-TB activity, (MIC $6.25 \mathrm{mg} / \mathrm{ml}$ ), while other fractions were resistant. This result gives a very useful insight to the fraction that could be used in extracting active ingredients from the leaf of Bidens pilosa in the treatment of tuberculosis. 
Table 5 Presence of resistant and sensitive strains from BP leaf extract against Mycobacterium tuberculosis isolate during seven weeks

\begin{tabular}{lcccccccc}
\hline BP leaf extract & DS-MTB & DS-MTB & DS-MTB & DS-MTB & DS-MTB & DR-MTB & DR-MTB & H37Rv \\
& & $\mathbf{1}$ & $\mathbf{2}$ & $\mathbf{3}$ & $\mathbf{4}$ & $\mathbf{5}$ & $\mathbf{1}$ & $\mathbf{2}$ \\
\hline Crude extract & $\mathrm{R}$ & $\mathrm{R}$ & $\mathrm{R}$ & $\mathrm{R}$ & $\mathrm{R}$ & $\mathrm{R}$ & $\mathrm{R}$ & $\mathrm{R}$ \\
Aqueous Fraction & $\mathrm{R}$ & $\mathrm{R}$ & $\mathrm{R}$ & $\mathrm{R}$ & $\mathrm{R}$ & $\mathrm{R}$ & $\mathrm{R}$ & $\mathrm{R}$ \\
Interface of Hexane/Methanol & $\mathrm{S}$ & $\mathrm{S}$ & $\mathrm{S}$ & $\mathrm{S}$ & $\mathrm{S}$ & $\mathrm{S}$ & $\mathrm{S}$ & $\mathrm{S}$ \\
Chloroform fraction & $\mathrm{R}$ & $\mathrm{R}$ & $\mathrm{R}$ & $\mathrm{R}$ & $\mathrm{R}$ & $\mathrm{R}$ & $\mathrm{R}$ & $\mathrm{R}$ \\
Methanolic fraction & $\mathrm{R}$ & $\mathrm{R}$ & $\mathrm{R}$ & $\mathrm{R}$ & $\mathrm{R}$ & $\mathrm{R}$ & $\mathrm{R}$ & $\mathrm{R}$ \\
Hexane fraction & $\mathrm{R}$ & $\mathrm{R}$ & $\mathrm{S}$ & $\mathrm{R}$ & $\mathrm{R}$ & $\mathrm{R}$ & $\mathrm{R}$ & $\mathrm{S}$ \\
\hline
\end{tabular}

Control drugs: susceptible - Rifampicin $(40 \mathrm{mg})$; resistant- Levofloxacin $(200 \mathrm{mg})$

Keys: DS-MTB - Drug susceptible Mycobacterium tuberculosis; DR-MTB - Drug resistant Mycobacterium tuberculosis; H37Rv = Mycobacterium tuberculosis strain; $\mathrm{S}=$ Sensitive; $\mathrm{R}=$ Resistant

The identified compounds using GC-MS analysis with their retention time (RT), molecular formula, molecular weight and abundance are presented in Table 6. The results of the GC-MS analyses of the crude extracts are shown in Figure 1. Identification of these compounds was confirmed by comparing the mass spectra obtained with literature mass spectra where available. The result indicated the presence of the volatile components in the methanolic extract of Bidens pilosa leaf: cis-9-Hexadecenal, 9-Oxabicyclo[6.1.0]nonane, Hexadecanoic acid methyl ester, Dodecanoic acid 10-methyl-methyl ester, 10,13-Octadecadienoic acid methyl ester, 9,12,15-Octadecatrienoic acid methyl ester (Z,Z,Z)-, Tetradecanal, 2-Methyl-Z,Z-3,13-octadecadienol, 13-Octadecenal (Z)- and Oleic acid. It is of interest to note that the compounds identified from the leaf extract have some form of biological activity. For instance, cis-9-Hexadecenal, is an aldehyde and has antimicrobial property while Hexadecanoic acid methyl ester, has antioxidant, hypocholesterolemic, nematicide, pesticide, antiandrogenic, flavour, hemolytic and 5-Alpha reductase inhibitor properties (Mujeeb et al., 2014) 9,12,15-Octadecatrienoic acid methyl ester(Z,Z,Z)-, has hepatoprotective, nematicide, insectifuge antihistaminic, antiarthritic, anticoronary, antieczemic antiacne, 5-alpha reductase inhibitor antiandrogenic properties (Bartolome et al. 2013). It was also observed that Tetradecanal, is an aldehyde with antifungal, antioxidant, cancer preventive, nematicide, hypercholesterolemic, lubricative properties (Mujeeb et al., 2014) while 13-Octadecenal (Z), is an aldehyde and Oleic acid, both exhibit antibacterial properties (Duke, 1992; Bartolome et al., 2013 ). The bioactive compounds identified in the leaf part of the plant justifies its ethnobotanical claims.

Table 6 GC-MS analysis of methanolic extract of Bidens pilosa leaf

\begin{tabular}{|c|c|c|c|c|c|}
\hline S.No. & Ret.Time & Compound & $\begin{array}{c}\text { Molecular weight } \\
(\mathrm{g} / \mathrm{mol})\end{array}$ & Molecular formula & Abundance (\%) \\
\hline 1 & 1.196 & cis-9-Hexadecenal & 238.415 & $\mathrm{C}_{16} \mathrm{H}_{30} \mathrm{O}$ & 95 \\
\hline 2 & 1.196 & 9-Oxabicyclo[6.1.0] nonane & 126.199 & $\mathrm{C}_{8} \mathrm{H}_{14} \mathrm{O}$ & 92 \\
\hline 3 & 24.261 & Hexadecanoic acid, methyl ester & 270.457 & $\mathrm{C}_{17} \mathrm{H}_{34} \mathrm{O}_{2}$ & 96 \\
\hline 4 & 24.261 & Dodecanoic acid & 201.314 & $\mathrm{C}_{12} \mathrm{H}_{24} \mathrm{O}_{2}$ & 90 \\
\hline 5 & 26.160 & 10,13-Octadecadienoic acid, methyl ester & 294.47 & $\mathrm{C}_{19} \mathrm{H}_{34} \mathrm{O}_{2}$ & 99 \\
\hline 6 & 26.252 & 9,12,15-Octadecatrienoic acid, methyl ester(Z,Z,Z)- & 292.4562 & $\mathrm{C}_{19} \mathrm{H}_{32} \mathrm{O}_{2}$ & 99 \\
\hline 7 & 33.462 & Tetradecanal & 212.377 & $\mathrm{C}_{14} \mathrm{H}_{28} \mathrm{O}$ & 93 \\
\hline 8 & 34.612 & 2-Methyl-Z,Z-3,13-octadecadienol & 280.496 & $\mathrm{C}_{19} \mathrm{H}_{36} \mathrm{O}$ & 95 \\
\hline 9 & 37.456 & 13-Octadecenal, (Z)- & 266.469 & $\mathrm{C}_{18} \mathrm{H}_{34} \mathrm{O}$ & 90 \\
\hline 10 & 43.063 & Oleic Acid & 282.47 & $\mathrm{C}_{18} \mathrm{H}_{34} \mathrm{O}_{2}$ & 91 \\
\hline
\end{tabular}

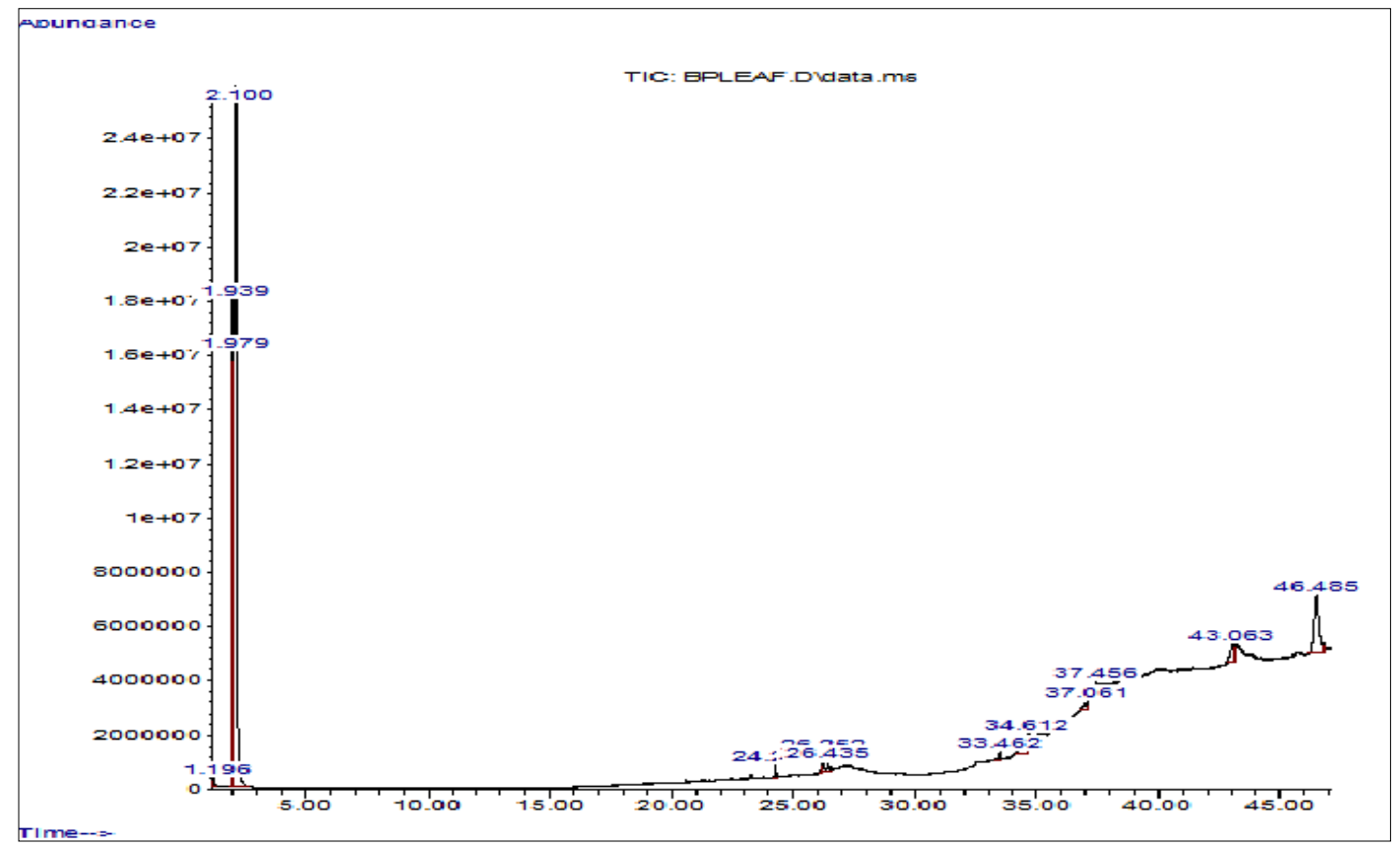

Figure 1 Gas Chromatogram of methanolic extract of Bidens pilosa leaf

\section{CONCLUSION}

The potentiality of Bidens pilosa leaf as enhancement formulation in the treatment of tuberculosis has been explored in this study. The results obtained from the phytochemical screening revealed the abundancy of alkaloids, tannins, terpenoids, cardiac glycosides and steroids. This confirms previous studies carried out on $B$. pilosa by Silva $\boldsymbol{e t}$ al, 2011. The alkaloids present in the leaf is an indication that the leaf could be used as an analgesics and anti-malaria. Tannins was established to be present in the $B P$ leaf which makes the leaf potent as antioxidants, anti-fungal and anti-virus properties. Terpenoids, such as 
steroids, lupeol, oleanolic acid are known to possess sedative and anti-depressive effects, and this was found to be present in the leaf. The presence cardiac glycosides is an indication of its usefulness in the treatment of heart failure. The GC-MS studies carried out on the methanolic extract of Bidens pilosa showed the presence of bioactive compounds responsible for the potent activity of the plant The plant serves as a potential source for drug formulation as a result of its antimicrobial and anti-tubercular properties.

Acknowledgements: The authors would like to gratefully acknowledge Covenant University for the grant support given for this study and also to the staff of Multi-user laboratory, Ahmadu Bello University, Zaria for the use of laboratory facilities.

\section{REFERENCES}

ADEBAYO, A., BALADE, A., YAKUBU, O. 2017. Gas chromatography-mass spectrometry analysis of viburnum opulus (L) extract and its toxicity studies in rats. Asian Journal of pharmaceutical and clinical research, 10(6), 383-388 http://dx.doi.org10.22159/ajpcr.2017.v10i6.17350

AIBINU, I., ADENIPEKUN, T., ADELOWOTAN, T., OGUNSANYA, T. ODUGBEMI, T. 2007. Evaluation of the Antimicrobial Properties of Different Parts of Citrus Aurantifolia (Lime Fruit) as Used Locally. African journal of traditional, complementary, and alternative medicines, 4(2), 185-190.

BARTOLOME, A., VILLASENOR, M., YANG, W. 2013. Bidens pilosa L. (Asteraceae): Botanical Properties, Traditional Uses, Phytochemistry, and Pharmacology. Evidence-Based Complementary and Alternative Medicine, 2013 1-51. http://dx.doi.org/10.1155/2013/340215

SATHISHKUMAR, T., BASKAR, S. 2014. Screening and quantification of phytochemicals in leaves and flowers of Tabernaemontana heyneana. Indian Journal of Natural Products and Resources, 237-243.

CONNELLY, P. 2009. Horrible weed or miracle herb? A review of Bidens pilosa. Journal of the Australian Traditional-Medicines Society, 15(2), 77-79.

COOPER, R. 2015. Natural product chemistry, sources, separations and structures. 6000 broken sound parkway NW, Suite 300 Boca raton: CRC press.

DEWANTO, V., WU, X., ADOM, K.K., LIU R.H. 2002. Thermal processing enhances the nutritional value of tomatoes by increasing total antioxidant activity. J. Agric. Food Chem., 50(10), 3010-3014.

DEBA, F., XUAN, T.D., YASUDA, M., TAWATA, S. 2008. Chemical composition and antioxidant, antibacterial and antifungal activities of the essential oils from Bidens pilosa Linn. var. Radiata. Food Control, 19(4): 346352, 2008. https://doi.org/10.1016/i.foodcont.2007.04.011

DUKE, J. 1992. Handbook of Biologically Active Phytochemicals and Thir Activities, CRC Press, 1992.

FEDERAL MINISTRY OF HEALTH 2009. Acid fast direct smear microscopy, National Tuberculosis and Leprosy control programme, 9-15. FUJIKI, A. 2001. Culture examination for M. tuberculosis. In, TB Bacteriology Examination to stop TB. (ed). Pp 14-19.

HAMILTON, A.C. 2004. Medicinal plants, conservation and livelihoods. $\begin{array}{llrl}\text { Biodiversity and } & \text { Conservation. } & 13(8), & 1477-1517\end{array}$ https://doi.org/10.1023/B:BIOC.0000021333.23413.42

IJEH, I.I., NJOKU, O.U., EKENZE, E.C. 2004. Medicinal evaluation of Xylopia aethiopica and Ocimum gratissimum. J. Med. Aromatic Sci. 26(1), 44-47.

KUMAR, V., ABUL, K., FAUSTO, N., MITCHELL, R. 2007. Robbins Basic Pathology (8th ed.). Saunders Elsevier. pp. 516-522.

LADAN, Z., AMUPITAN, J.O., OYEWALE, O.A., AYO, R.G., TEMPLE, E., LADAN, E.O. 2014. Phytochemical screening of the leaf extracts of Hyptis spicigera plant. African journal of pure and applied chemistry, 8(5), 83-88.

MAHESH, B., SATISH, S. 2008. Antimicrobial activity of some important medicinal plant against plant and human pathogens. World J. Agric. Sci., 4: 839843.

MUJEEB, F., BAJPAI, P., PATHAK, N. 2014. Phytochemical evaluation, antimicrobial activity, and determination of bioactive components from leaves of Aegle marmelos. BioMed. Research International, vol. 2014, Article ID 497606, 11 pages, 2014. http://dx.doi.org/10.1155/2014/497606

NKAFAMIYA, I.I., MANJI, A.J. 2006. A study of cyanogenetic glucoside content of ome edible nuts and seeds. J.Chem.Soc.Niger, 31(1\&2), 12-14.

NWEZE, E.I., OKAFOR, J.I., NJOKU, O. 2004. Antimicrobial activities of methanolic extracts of Trema guinensis (Schumm and Thorn) and Morinda Lucida Benth used in Nigeria. Bio-Research 2(1), 39-46.

OLUGBUYIRO, J.A.O., MOODY, J.O., HAMANN, M.T. 2009. Anti-Mtb activity of triterpenoid-rich fractions from Spondiasmombin L.. Afri J Biotechnol, 8(9), 1807-1809.

KALITA, P., BARMAN, T.K., PAL, T.K., KALITA, R. 2013. Estimation of total flavonoids content (TFC) and anti-oxidant activities of methanolic whole plant extract of Biophytum sensitivum linn. Journal of Drug Delivery \& Therapeutics, 3(4), 33-37.

KUMAR, R.R., JADEJA, V.J. 2016. Endophytic Actinomycetes: A Novel Antibiotic Source. Int. J. Curr. Microbiol. App. Sci. 5(8), 164-175. http://dx.doi.org/10.20546/ijcmas.2016.508.018
SANCHEZ, J.G.B., KOUZNETSOV, V.V. 2010. Antimycobacterial susceptibility testing methods for natural products research. Braz. J. Microbiol. 41(2): 270-277 doi: 10.1590/S1517-83822010000200001.

SHAKERI, A., HAZERI, N., VLIZADEH, J., GHASEMI, A., TAVALLAEI, F.Z. 2012. Photochemical screening, antimicrobial and antioxidant activity of Anabasis aphylla L. Extracts. Kragujevac Journal of Science, 34, 71-78.

SILVA, F.L., FISCHER, D.C., TAVARES, J.F., SILVA, M.S., DE-ATHAYDEFILHO, P.F., BARBOSA-FILHO, J.M. 2011. Compilation of secondary metabolites from Bidens pilosa L. Molecules, 16(2), 1070-1102. http://dx.doi.org/10.3390/molecules. 16021070

SOFOWORA, A. 1996. Research in medicinal plants and traditional medicine in Africa. The Journal of Alternative and Complementary Medicine, 2(3), 365-372 https://doi.org/10.1089/acm.1996.2.365

WHO (World Health Organization). 2002. Traditional medicine strategy. 2002 2005. Geneva: World Health Organization; 2002.

YANG, W. 2014. Botanical, pharmacological, phytochemical, and toxicological aspects of the antidiabetic plant Bidens pilosa L. Evidence-Based Complementary and Alternative Medicine Volume 2014, Article ID 698617, 14 pages. http://dx.doi.org/10.1155/2014/698617 